\title{
16S rRNA sequence analysis of an isolate of Mycobacterium haemophilum from a heart transplant patient
}

\author{
CATHERINE H. ZAPPE*, DIANA BARLOW $\dagger$, H. ZAPPE* $\dagger$, INGRID J. BOLTON $\dagger$, DENISE RODITI* $\dagger$ \\ and L. M. STEYN* ${ }^{*} \ddagger$
}

* Department of Medical Microbiology, University of Cape Town and † Groote Schuur Hospital, Anzio Road, Observatory, 7925 South Africa

\begin{abstract}
Summary. Biopsy samples from a heart transplant patient with cellulitis and bursitis yielded an isolate of Mycobacterium haemophilum. The isolate was identified on the basis of a growth requirement for haemin or ferric ammonium citrate, growth at $30^{\circ} \mathrm{C}$ but not at $37^{\circ} \mathrm{C}$, negative catalase test, intracellular growth in $\mathrm{McCoy}$ fibroblasts and sequence identity with a portion of the 16S rRNA sequence of the type strain. In comparisons with known 16S rRNA sequences, $M$. haemophilum grouped with other pathogenic, slow-growing mycobacteria, showing close sequence similarity to M. marinum $(98.8 \%)$ and lower similarity to $M$. ulcerans and $M$. tuberculosis complex organisms. $M$. haemophilum and $M$. marinum share other features including optimal growth at $30^{\circ} \mathrm{C}$ and the ability to cause superficial skin lesions in man.
\end{abstract}

\section{Introduction}

Mycobacterium haemophilum is a slow-growing, strongly acid- and alcohol-fast bacillus, first described by Sompolinsky et al., ${ }^{1}$ that requires haemin or ferric ammonium citrate for growth, ${ }^{2}$ shows no detectable catalase activity and grows optimally at $30^{\circ} \mathrm{C}$. In contrast to other slow-growing mycobacteria that grow on McCoy fibroblasts, $M$. haemophilum grows intracellularly in these cells. ${ }^{4}$ It is an opportunist pathogen most commonly isolated from superficial skin lesions in organ transplant patients. ${ }^{5}$ Infections have also been documented in three AIDS patients, two with disseminated infection and one with tenosynovitis. $^{6,7}$ The true incidence of infection with $M$. haemophilum may be underestimated because of its fastidious growth requirements, but the incidence will probably increase with the rising number of HIVpositive patients.

Wayne and Sramek speculated that $M$. haemophilum could be a biochemically inert or fastidious subspecies of $M$. avium. ${ }^{5}$ In this report, $16 \mathrm{~S}$ rRNA gene sequence data for an isolate of $M$. haemophilum are presented and compared with known sequences for other mycobacteria.

\section{Materials and methods}

\section{Isolation and identification}

Skin and cephalic vein biopsy samples from the right arm of a heart transplant patient with cellulitis and bursitis of his right elbow were submitted to the microbiology laboratory, Groote Schuur Hospital, for routine bacterial and mycobacterial culture. Standard bacterial and mycobacterial culture media were inoculated, along with Lowenstein and Jensen slopes (LJ) with and without ferric ammonium citrate (FAC, $15 \mathrm{mg} / \mathrm{ml}){ }^{2}$ The latter were cultured at $30^{\circ} \mathrm{C}$.

Identification tests comprised: Gram and ZiehlNeelsen (ZN) stains; confirmation of growth temperature range and iron dependence by subculture on LJ with and without FAC incubated at $30^{\circ} \mathrm{C}$ and $37^{\circ} \mathrm{C}$; culture on boiled horse blood $5 \%$ agar slopes incubated aerobically and in a candle jar at $30^{\circ} \mathrm{C}$; culture on a confluent monolayer of McCoy fibroblasts stained for acid- and alcohol-fast bacilli after incubation for $4,6,8$ and 10 days at $30^{\circ} \mathrm{C} ;{ }^{1}$ and tests for niacin production, catalase (semi-quantitative), nitrate reduction, urease, Tween 80 hydrolysis and arylsulphatase activity. ${ }^{8}$

\section{Cloning of the M. haemophilum $16 S$ rRNA gene}

The Escherichia coli $\mathrm{pUC1} 19$ vector was used in all cloning experiments. ${ }^{9}$ Chromosomal DNA was purified from $M$. haemophilum as described previously. ${ }^{10}$ 
The 16S rRNA gene was amplified by PCR with the bacterial small subunit ribosomal primers $\mathrm{pA}$ and $\mathrm{pH} .{ }^{11}$ The reaction mixture contained: $2 \mathrm{mM}$ of each dNTP; 2 units of $T a q$ polymerase (Boehringer Mannheim); 100 pmols of each primer; and $10 \mu \mathrm{l}$ of genomic DNA (c. $100 \mathrm{ng}$ ) in $50 \mu \mathrm{l}$ of Taq buffer (Boehringer Mannheim) overlaid with $50 \mu$ lof mineral oil. This was incubated at $95^{\circ} \mathrm{C}$ for $5 \mathrm{~min}$, then subjected to 35 cycles of: $93^{\circ} \mathrm{C}$ for $20 \mathrm{~s}$ (denaturation), $60^{\circ} \mathrm{C}$ for $30 \mathrm{~s}$ (annealing) and $72^{\circ} \mathrm{C}$ for $60 \mathrm{~s}$ (primer extension). The amplified product was separated by agarose gel electrophoresis, eluted from the ge ${ }^{12}$ and cloned by the T-A cloning method. Briefly, this method exploits the template-independent terminal transferase activity of $T a q$ polymerase which results in the addition of a single adenosine, or, in conditions where only thymidine is provided, a single thymidine to the $3^{\prime}$ end of the PCR production during amplification. ${ }^{13}$ $\mathrm{T}$-tailed vector was made by use of this activity by incubating blunt-ended pUC19 $(1 \mu \mathrm{g})$ for $2 \mathrm{~h}$ at $70^{\circ} \mathrm{C}$ with Taq polymerase ( $1 \mathrm{U}$ ) and dTTP $(2 \mathrm{mM})$ in $20 \mu \mathrm{l}$ of Taq buffer. Ligation of the PCR products to a $T$-tailed vector resulted in cloning efficiencies similar to sticky-end cloning. ${ }^{14}$

\section{Sequence determination}

The cloned 16S rRNA gene was sequenced (Pharmacia ${ }^{\mathrm{T}}$ Sequencing Kit) by the dideoxy method. ${ }^{15}$ The DNA insert was mapped and restriction fragments were subcloned in pUC19 for sequencing with $\mathrm{M} 13 / \mathrm{pUC1} 19$ universal primers. Where no suitable restriction sites were available for subcloning, custom primers were synthesised. The gene was sequenced in both orientations.

\section{Data analysis}

The sequence was compared with known sequences deposited in the Ribosomal Database Project (RDP) with the SIMILARITY-RANK program which finds similar deposited sequences, and the ALIGNSEQUENCE program. ${ }^{16}$ A mycobacterial phylogenetic tree was generated (courtesy of Ross Overbeek, RDP) and percentage similarities for the organisms clustered with $M$. haemophilum were calculated with the FASTA programme. ${ }^{17}$ The $M$. haemophilum sequence was submitted to GenBank, accession number U06638.

\section{Results and Discussion}

The patient, a 54-year-old male, was admitted to Groote Schuur Hospital in February 1988 with endstage cardiac failure after previous myocardial infarctions. He received a heart transplant and was discharged 2 weeks later without any evidence of tissue rejection. Three months later he developed cellulitis over his right elbow while receiving azathioprine $150 \mathrm{mg}$ daily, methyl prednisolone $14 \mathrm{mg}$ twice daily and cyclosporine $1.9 \mathrm{ml}$ twice daily. At biopsy of the infected skin and basilic vein, the vein was found to be thrombosed and acid-fast bacilli were found in the biopsy specimens. Anti-tuberculous therapy with daily rifampicin $600 \mathrm{mg}$, isoniazid $400 \mathrm{mg}$, pyrazinamide $2 \mathrm{~g}$ and ethambutol $1.2 \mathrm{~g}$, was started. Due to the difficulty in controlling the infection, and because there was no evidence of tissue rejection, the methyl prednisolone was stopped. The cellulitis steadily improved and within 2 months after initiation of antituberculous therapy, no evidence of inflammation was present. The patient was re-admitted 2 months later with severe shortness of breath and bilateral lung infiltrates due to cytomegalovirus infection. His clinical course was stormy and, after several septicaemic episodes, he died in septicaemic shock. At autopsy no suppurative disease was noted, but no material was submitted for bacterial culture.

The initial skin and vein biopsies contained numerous acid- and alcohol-fast bacilli seen on direct microscopy, but yielded no growth from routine cultures, nor from mycobacterial cultures other than those on LJ with FAC incubated at $30^{\circ} \mathrm{C}$. After incubation for 4 weeks on this medium, non-pigmented, buff coloured, smooth colonies were observed. The organism was a weakly staining gram-positive bacillus, strongly acid- and alcohol-fast, with erratic, short cording. Iron dependence and growth temperature range were confirmed by subculture on $\mathrm{LJ}$ with and without $\mathrm{FAC}$ at $30^{\circ} \mathrm{C}$ and $37^{\circ} \mathrm{C}$. Cultures at $30^{\circ} \mathrm{C}$ on boiled blood agar yielded rough, waxy colonies with an undulating surface. $\mathrm{CO}_{2}$ enrichment did not enhance growth, in contrast to earlier descriptions. ${ }^{18}$ Culture on McCoy cells showed intracellular acid-and alcohol-fast bacilli, most evident after incubation for 4 days. Biochemical tests gave negative results, with the exception of nitrate reductase, which was weakly positive. These characteristics supported an identification of the isolate as $M$. haemophilum - particularly the negative catalase test which distinguishes $M$. haemophilum from $M$. marinum and M. ulcerans. ${ }^{3}$

The sequence of the cloned 16S rRNA gene was 1489-bp long, excluding the universal primer sequences. Comparison with known 16S rRNA gene sequences placed $M$. haemophilum in a cluster with other slow-growing pathogenic mycobacteria comprising $M$. marinum, $M$. ulcerans, $M$. tuberculosis, $M$. bovis and M. leprae (table). M. marinum (X52920) showed the closest similarity $(98 \cdot 8 \%)$, with sequence divergence mainly in the region between bases 137 and 152 ( 9 of 16 mismatches; figure). PCR amplification and direct sequencing of this region from the type strain of $M$. haemophilum (ATCC 29548) yielded a sequence identical to that obtained for the clinical isolate. The 16S rRNA sequence for another, otherwise undescribed, $M$. haemophilum isolate (GenBank accession number L24800) showed only $98.8 \%$ similarity with our isolate, with differences scattered, apparently randomly, through the sequences. Similarities in the phenolic 1-glycolipid antigens and fatty acid profiles of $M$. haemophilum and $M$. leprae have been noted. ${ }^{19,20} \mathrm{~A}$ similarity of $98.0 \%$ in $16 \mathrm{~S}$ 
Table. Similarities in 16S rRNA gene sequences for the mycobacteria showing closest sequence similarity to M. haemophilum

\begin{tabular}{|c|c|c|c|c|c|c|c|c|c|}
\hline \multirow{2}{*}{ Species } & \multirow{2}{*}{$\begin{array}{l}\text { GenBank } \\
\text { accession } \\
\text { number }\end{array}$} & \multicolumn{8}{|c|}{ Similarity $(\%)$ of aligned $16 \mathrm{~S}$ rRNA sequence with } \\
\hline & & M20940 & X55589 & L24800 & U06638 & X55587 & X52920 & X52917 & Z13990 \\
\hline M. bovis & M20940 & $100 \cdot 0$ & & & & & & & \\
\hline M. bovis & X55589 & $99 \cdot 6$ & $100 \cdot 0$ & & & & & & \\
\hline M. haemophilum & L24800 & $97 \cdot 7$ & $97 \cdot 3$ & $100 \cdot 0$ & & & & & \\
\hline M. haemophilum & U06638 & $98 \cdot 6$ & $98 \cdot 2$ & $98 \cdot 8$ & $100 \cdot 0$ & & & & \\
\hline M. leprae & X55587 & $96 \cdot 6$ & $96 \cdot 3$ & $96 \cdot 3$ & $98 \cdot 0$ & $100 \cdot 0$ & & & \\
\hline$M$. marinum & X52920 & $99 \cdot 1$ & $98 \cdot 8$ & $97 \cdot 8$ & $98 \cdot 8$ & $96 \cdot 5$ & $100 \cdot 0$ & & \\
\hline M. tuberculosis & X52917 & 99.9 & $99 \cdot 6$ & $97 \cdot 6$ & $98 \cdot 6$ & 96.6 & $99 \cdot 0$ & $100 \cdot 0$ & \\
\hline M. ulcerans & Z13990 & $98 \cdot 2$ & $98 \cdot 0$ & $97 \cdot 0$ & $97 \cdot 8$ & $95 \cdot 6$ & $99 \cdot 0$ & $98 \cdot 2$ & $100 \cdot 0$ \\
\hline M. ulcerans & X58954 & $99 \cdot 0$ & $98 \cdot 7$ & $97 \cdot 7$ & $98 \cdot 7$ & $96 \cdot 4$ & $99 \cdot 9$ & $99 \cdot 0$ & $99 \cdot 1$ \\
\hline
\end{tabular}

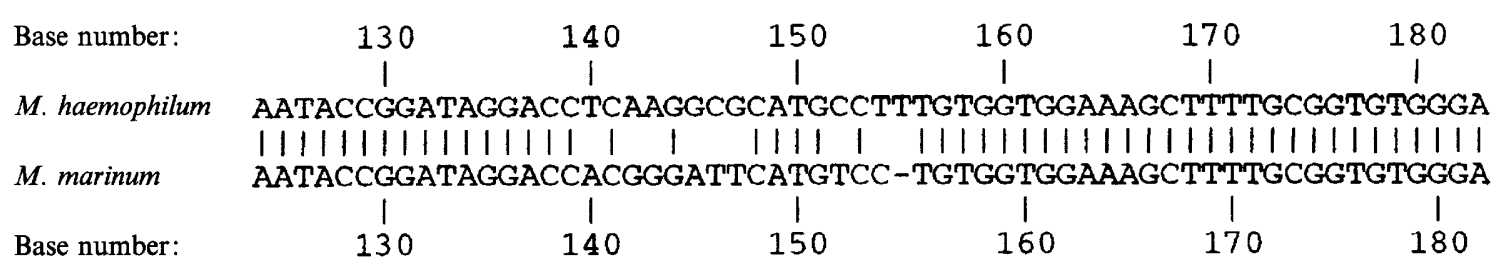

Figure. Alignment of the portion of the $16 \mathrm{~S}$ rRNA gene sequences showing maximal sequence divergence between the $M$. haemophilum isolate (U06638) and M. marinum (X52920).

rRNA sequences for $M$. leprae (X55587) and our $M$. haemophilum isolate was found, making this the closest neighbour of $M$. leprae.

The close similarity of $M$. haemophilum and $M$. marinum sequences was unexpected, as it has been suggested that $M$. haemophilum is related to the $M$. avium complex. ${ }^{5}$ However, $M$. marinum also causes infections that tend to be limited to skin surfaces, ${ }^{5}$ and shows optimum growth at $30^{\circ} \mathrm{C}$, which may be the reason for superficial dissemination of these infections.

\section{References}

1. Sompolinsky D, Lagziel A, Naveh D, Yankilevitz T. Mycobacterium haemophilum sp. nov., a new pathogen of humans. Int J Syst Bacteriol 1978; 28: 67-75.

2. Dawson DJ, Jennis F. Mycobacteria with a growth requirement for ferric ammonium citrate, identified as Mycobacterium haemophilum. J Clin Microbiol 1980; 11: 190-192.

3. Moulsdale MT, Harper JM, Thatcher GN, Dunn BL. Infection by Mycobacterium haemophilum, a metabolically fastidious acid-fast bacillus. Tubercle 1983; 64: 29-36.

4. Sompolinsky D, Lagziel A, Rosenberg I. Further studies of a new pathogenic mycobacterium $(M$. haemophilum $\mathrm{sp}$. nov.). Can J Microbiol 1979; 25: 217-226.

5. Wayne LG, Sramek HA. Agents of newly recognized or infrequently encountered mycobacterial diseases. Clin Microbiol Rev 1992; 5: 1-25.

6. Rogers PL, Walker RE, Lane $\mathrm{HC}$ et al. Disseminated $M y c o-$ bacterium haemophilum infection in two patients with the acquired immunodeficiency syndrome. Am J Med 1988; 84: $640-642$.

7. Males BM, West TE, Bartholomew WR. Mycobacterium haemophilum infection in a patient with acquired immune deficiency syndrome. J Clin Microbiol 1987; 25: 186-190.

8. Kleeberg HH, Koornhof HJ, Palmhert H. Laboratory manual of tuberculosis methods, 2nd edn. Pretoria: 1980.

9. Yanisch-Perron C, Vieira J, Messing J. Improved M13 phage cloning vectors and host strains: nucleotide sequences of the M13mp1 8 and pUC19 vectors. Gene 1985 ; 33: 103-119.

10. De Wit D, Steyn L, Shoemaker S, Sogin M. Direct detection of Mycobacterium tuberculosis in clinical specimens by DNA amplification. J Clin Microbiol 1990; 28: 2437-2441.
It may be informative to investigate the host range of $M$. haemophilum in cold-blooded vertebrates, to establish whether these species occupy a similar ecological niche.

We thank Professor A. Forder, Department of Medical Microbiology, Groote Schuur Hospital, for his encouragement and support, the Department of Cardio-thoracic Surgery for clinical information, R. Overbeek for the mycobacterial phylogenetic tree and Dr Gay Elisha for her comments on the manuscript. This work was supported by grants from the Medical Research Council, University of Cape Town and DG Murray Trust.
11. Edwards U, Rogall T, Blocker H, Emde M, Bottger EC. Isolation and direct complete nucleotide determination of entire genes. Characterization of a gene coding for $16 \mathrm{~S}$ ribosomal RNA. Nucleic Acids Res 1989; 17: 7843-7853.

12. Hansen H, Lemke H, Bodner U. Rapid and simple purification of PCR products by direct band elution during agarose electrophoresis. Biotechniques 1993; 14: 28-30.

13. Clark JM. Novel non-templated nucleotide addition reactions catalyzed by procaryotic and eucaryotic DNA polymerases. Nucleic Acids Res 1988; 16: 9677-9686.

14. Marchuk D, Drumm M, Saulino A, Collins FS. Construction of T-vectors, a rapid and general system for direct cloning of unmodified PCR products. Nucleic Acids Res 1991; 19: 1154.

15. Sanger F, Nicklen $S$, Coulson AR. DNA sequencing with chainterminating inhibitors. Proc Natl Acad Sci USA 1977; 74: 5463-5467.

16. Larsen N, Olsen GJ, Maidak BL et al. The ribosomal database project. Nucleic Acids Res 1993; 21: 3021-3023.

17. Pearson WR. Rapid and sensitive sequence comparison with FASTP and FASTA. In: Doolittle RF (ed) Methods in enzymology, 183. London, Academic Press. 1990: 63-98.

18. Ryan CG, Dwyer BW. New characteristics of Mycobacterium haemophilum. J Clin Microbiol 1983; 18: 976-977.

19. Besra GS, McNeil M, Minnikin DE, Portaels F, Ridell M, Brennan PJ. Structural elucidation and antigenicity of a novel phenolic glycolipid antigen from Mycobacterium haemophilum. Biochemistry 1991; 30: 7772-7777.

20. Portaels F, Dawson DJ, Larsson L, Rigouts L. Biochemical properties and fatty acid composition of Mycobacterium haemophilum: study of 16 isolates from Australian patients. J Clin Microbiol 1993; 31: 26-30. 